\title{
The effect of reaction conditions on the precipitation of sodium hexafluorosilicate produced from waste hexafluorosilicic acid
}

\author{
Marwan M. Batiha1, Mohammad Al-Harahsheh ${ }^{2}$ \\ ${ }^{1}$ Faculty of Engineering, Department of Chemical Engineering, Al-Hussein Bin Talal University, Ma'an, Jordan, e-mail: \\ mmbatiha@ahu.edu.jo \\ ${ }^{2}$ Faculty of Engineering, Department of Mining Engineering, Al-Hussein Bin Talal University, Ma'an, Jordan
}

\begin{abstract}
The purpose of the study is to investigate the optimum conditions for the precipitation of sodium hexafluorosilicate $\left(\mathrm{Na}_{2} \mathrm{SiF}_{6}\right)$ from waste hexafluorosilicic acid, an effluent from the phosphoric acid industry. Sodium chloride and sodium hydroxide were used as reactants to produce $\mathrm{Na}_{2} \mathrm{SiF}_{6}$. The effect of various parameters on the precipitation was investigated and includes; the molar ratio of the reactants, contact time, the temperature and the effect of seeding.

The optimum reaction conditions were found to be as follows; excess sodium chloride or sodium hydroxide to hexafluorosilicic acid of $25 \%$, contact time 40 minutes and a reaction temperature of $40^{\circ} \mathrm{C}$.

The reaction of hexafluorosilicic acid with an aqueous solution of sodium chloride at optimum conditions gave a maximum yield of $94.26 \% \mathrm{Na}_{2} \mathrm{SiF}_{6}$ while the reaction of hexafluorosilicic acid with the aqueous solution of sodium hydroxide at optimum conditions gave a maximum yield of $97.3 \% \mathrm{Na}_{2} \mathrm{SiF}_{6}$. The X-Ray diffraction (XRD) analysis reveals that the only crystals present in the precipitate are $\mathrm{Na}_{2} \mathrm{SiF}_{6}$. Also, Scanning Electron Microscope (SEM) analysis shows that the different morphology of these crystals depend on the precipitation conditions.
\end{abstract}

Keywords: Sodium hexafluorosilicate; reaction conditions; hexafluorosilicic acid, fertilizer industry.

\section{INTRODUCTION}

Sodium hexafluorosilicate is an odorless, white powder of hexagonal crystals $\left(\mathrm{MW}=188.06\right.$, density $\left.=2.679 \mathrm{~g} / \mathrm{cm}^{3}\right)$. It is used as a fluoridation agent for drinking water ${ }^{1}$, insecticide, rodenticide and veterinary treatment for lice $^{2}$, production of high purity silicon tetrafluoride ${ }^{3}$, and the production of enamels for china and porcelain products. Sodium hexafluorosilicate is used widely in industry, for a selective removal of surface acidity in zeolite ZSM-5, in photovoltaic applications ${ }^{4}$, synthesis of mesoporous silica ${ }^{5}$, dealumination of MCM-22 zeolite and ferrietite, as active agents in the formulation of mouth washes and dentifrices, synthesis of advanced ceramic materials ${ }^{6}$, and as catalysis products in the frosted glass industry ${ }^{7}$.

Sodium fluorosilicate is produced by the neutralization of hexafluorosilicic acid with sodium hydroxide, sodium carbonate, or sodium chloride under vigorous agitation conditions. The type of conversion depends on the concentration of the waste acid and the availability of neutralization materials. Besides, it is important to find a procedure to prevent gelatinization of the precipitate to assist filtration.

Jordan has huge reserves of phosphate rock. Currently phosphate rock is mined from three main locations; AlShediah, Al-Hesa and Al-Abiad. The annual production of phosphate is estimated to be 5.281 million tones during the year 2009, most of which is being exported and only less than $40 \%$ is being utilized locally to produce phosphoric acid. One of the main waste by-products of this industry is hexafluorosilicic acid. The amount of phosphate rock used in the production of phosphoric acid in the industrial fertilizers complex in Aqaba is approximately (1.0-1.2) million ton/year. This amount produces approximately (100.000-110.000) ton/year of hexafluorosilicic acid as a waste with a concentration of $(18-30 \%)^{8}$.
The importance of this study is to investigate the utilization of the waste hexafluorosilicic acid produced in the Industrial Fertilizers Complex in Aqaba - Jordan to produce sodium hexafluorosilicate based on the availability of the local sources, use a new feasible chemically and economically methods for the utilization of the available waste acid to avoid its accumulation in soil and underground water. Furthermore, the world prices and world demand on sodium hexafluorosilicate make the conversion economically attractive.

Although the production of hexafluorosilicate is a primitive process, however, the literature data available on this topic is limited ${ }^{9}$. The present work aims to study the various experimental conditions and parameters affecting the precipitation of sodium hexafluorosilicate. These parameters include the nature of the alkaline ion (sodium salt or sodium hydroxide), temperature, sodium salt or sodium hydroxide concentration, and contact time.

\section{MATERIALS AND METHODS}

Hexafluorosilicic acid sample of about 5 liters was obtained from the acid storage tank located in the phosphoric acid plant in Aqaba - Jordan. The sample was characterized for specific gravity, $\mathrm{H}_{2} \mathrm{SiF}_{6}$ and $\mathrm{HF}, \mathrm{HCl}$ concentrations, $\mathrm{P}_{2} \mathrm{O}_{5}$ and $\mathrm{Fe}_{2} \mathrm{O}_{3}$ contents. Sodium chloride and sodium hydroxide used were of reagent grade chemicals and obtained from ALFA AESAR ${ }^{\circledR}$.

Stock solutions of sodium chloride and sodium hydroxides $(5 \mathrm{M})$ were prepared and stored for further use. A volume of $25 \mathrm{ml}$ of $\mathrm{H}_{2} \mathrm{SiF}_{6}$ solution was added to 25 $\mathrm{ml}$ aliquot with the desired concentration of sodium chloride or sodium hydroxide. Prior to mixing, both solutions were heated to the desired temperature which was maintained until the end of the experiment using a thermostated water bath. The mixture was vigorously agitated at 300 rpm during the course of the experiment. At the end of the 
experiment the solid precipitate was separated by vacuum filtration using filter paper and then it was triple washed using distilled water. It was then dried at a temperature of $105^{\circ} \mathrm{C}$ for 3 hours. The dried precipitate was then weighed for yield calculation. The yield was calculated based on the theoretical amount of sodium hexafluorosilicate according to the following equations:

$2 \mathrm{NaCl}+\mathrm{H}_{2} \mathrm{SiF}_{6} \rightarrow \mathrm{Na}_{2} \mathrm{SiF}_{6}+2 \mathrm{HCl}$

$2 \mathrm{NaOH}+\mathrm{H}_{2} \mathrm{SiF}_{6} \rightarrow \mathrm{Na}_{2} \mathrm{SiF}_{6}+2 \mathrm{H}_{2} \mathrm{O}$

\section{RESULTS AND DISCUSSION}

The chemical analysis of hexafluorosilicic acid produced from the Industrial Fertilizers Complex in Aqaba (Jordan Phosphate Mines Company) is shown in Table 1.

Table 1. Chemical analysis of hexafluorosilicic acid produced from the Industrial Fertilizers Complex in Aqaba

\begin{tabular}{|l|c|}
\hline Specific gravity & 1.18 \\
\hline Concentration (wt \%) & 20.1 \\
\hline $\mathrm{HF}($ wt \%) & 0.76 \\
\hline $\mathrm{F}(\mathrm{wt} \%)$ & 16.64 \\
\hline $\mathrm{P}_{2} \mathrm{O}_{5}(\mathrm{mg} / \mathrm{L})$ & 300 \\
\hline $\mathrm{Cl}^{-}(\mathrm{ppm})$ & 9045 \\
\hline $\mathrm{Fe}_{2} \mathrm{O}_{3}(\mathrm{~g} / \mathrm{L})$ & 0.11 \\
\hline
\end{tabular}

The effects of various parameters affecting the precipitation of $\mathrm{Na}_{2} \mathrm{SiF}_{6}$ were studied as follows:

\section{Effect of $\mathrm{NaCl}$ and $\mathrm{NaOH}$ excess}

The effect of excess sodium chloride and sodium hydroxide/ hexafluorosilicic acid on the precipitation of sodium hexafluorosilicate was carried out at a temperature of $20^{\circ} \mathrm{C}$ and a contact time of 20 minutes (Fig. 1).

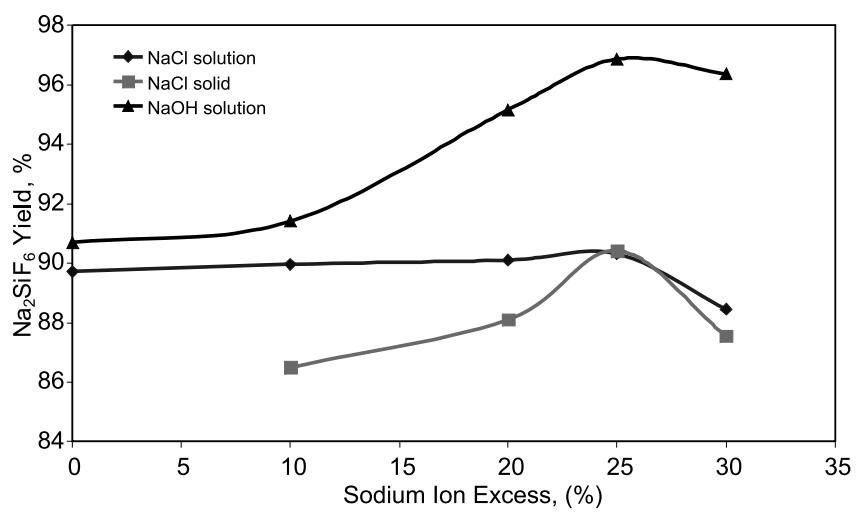

Figure 1. The effect of $\mathrm{Na}^{+}$excess on $\mathrm{Na}_{2} \mathrm{SiF}_{6}$ yield at the temperature of $20^{\circ} \mathrm{C}$ over $20 \mathrm{~min}$. reaction times

It was found that at $10 \%$ excess of solid $\mathrm{NaCl}$, the $\mathrm{Na}_{2} \mathrm{SiF}_{6}$ precipitate was of white color with a yield of $86.49 \%$. Filtration speed was slow and $\mathrm{pH}$ value of filtrate was acidic 1.42 . When the excess was increased to $20 \%$ the precipitate was also white in color and the yield increased to $88.1 \%$. The filtration speed was better and the $\mathrm{pH}$ value of the filtrate still acidic but dropped to 1.36 . In both cases above the solution produced was slightly turbid with dark yellow color which is related to the iron present in the $\mathrm{H}_{2} \mathrm{SiF}_{6}$ feed. At $25 \%$ excess the solution produced was not turbid, which led to a faster filtration process, with clear yellow color and the yield increased to
$90.42 \%$. The $\mathrm{pH}$ of the filtrate became more acidic and dropped further to 0.96 . However, when the excess was increased to $30 \%$ the product solution became much more turbid and thick of a yellowish color and the yield dropped to $87.55 \%$. The filtration process was very poor and the $\mathrm{pH}$ of the filtrate at this excess became more acidic and dropped further to 0.8 .

The drop of $\mathrm{Na}_{2} \mathrm{SiF}_{6}$ yield at $30 \%$ excess of solid sodium chloride is related to the increase in $\mathrm{HCl}$ concentration, as evident from the drop of the $\mathrm{pH}$ due to the reversible reaction (3), the formation of silica gel, and the product of polymerization of silicic acid ${ }^{\mathbf{1 0}}$.

$2 \mathrm{NaCl}(\mathrm{S})+\mathrm{H}_{2} \mathrm{SiF}_{6}-\mathrm{Na}_{2} \mathrm{SiF}_{6}+2 \mathrm{HCl}$

When hexafluorosilicic acid was added to a solution of sodium chloride the yield of $\mathrm{Na}_{2} \mathrm{SiF}_{6}$ was better at excess of 10 and $20 \%$ than that of solid form. The yield became then almost similar for solid and aqueous $\mathrm{NaCl}$ at excess of 25 and $30 \%$ (see Fig. 1). The maximum $\mathrm{Na}_{2} \mathrm{SiF}_{6}$ yield was $90.32 \%$ which is obtained at $25 \%$ excess.

The effect of sodium hydroxide excess $(10,20,25$, and $30 \%$ ) on the production of $\mathrm{Na}_{2} \mathrm{SiF}_{6}$ is shown also in Fig. 1. It is clear that the yield is increased with increasing sodium hydroxide excess reaching its maximum value of $96.86 \%$ at $25 \%$ excess. The yield then decreased when the excess was increased to $30 \%$. This could be related to the formation of soluble $\mathrm{NaF}^{5,11}$.

In all cases of sodium hydroxide reaction with $\mathrm{H}_{2} \mathrm{SiF}_{6}$, the color of the permeate was colorless, which is related to the absence of $\mathrm{Fe}^{3+}$ ions in the permeate as a result of its precipitation in the form $\mathrm{Fe}(\mathrm{OH})_{3}$.

\section{Effect of contact time}

The effect of contact time on the yield of $\mathrm{Na}_{2} \mathrm{SiF}_{6}$ was studied at $25 \%$ excess of $\mathrm{NaCl}$ and $\mathrm{NaOH}$ and at a temperature of $20^{\circ} \mathrm{C}$. It can be seen from Fig. 2 that the time required to reach the highest yield was 40 minutes. The maximum yield obtained in the case of $\mathrm{NaCl}$ was $94.01 \%$, whereas, it reached $97.3 \%$ when $\mathrm{NaOH}$ was used. After 40 minutes the yield dropped in both cases. The decrease in the yield after prolonged agitation when $\mathrm{NaCl}$ was used may be explained by dissolving some of the product in the $\mathrm{HCl}$ produced during the reaction. Frayret et al 7 reported the solubility of $\mathrm{Na}_{2} \mathrm{SiF}_{6}$ increases with the increase of $\mathrm{HCl}$ concentration reaching a maximum solubility value of $0.066 \mathrm{M}$ at $1 \mathrm{M} \mathrm{HCl}$ and a temperature of $20^{\circ} \mathrm{C}$, then it drops steadily reaching a $0.05 \mathrm{M}$ at $3 \mathrm{M} \mathrm{HCl}$. However, the solubility of $\mathrm{Na}_{2} \mathrm{SiF}_{6}$ in water at $20^{\circ} \mathrm{C}$ was reported to be $0.036 \mathrm{M}^{7,12}$. The other evidence of the back dissolu-

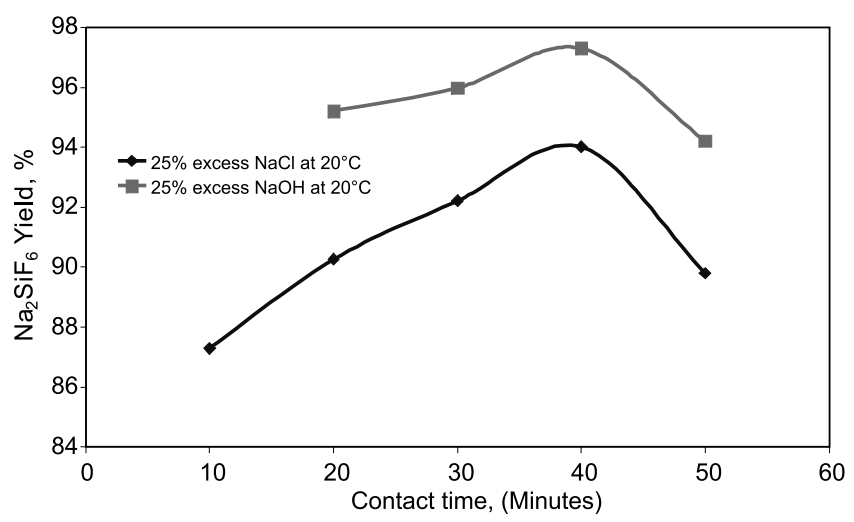

Figure 2. The effect of contact time on $\mathrm{Na}_{2} \mathrm{SiF}_{6}$ yield at the temperature of $20{ }^{\circ} \mathrm{C}$ and $25 \% \mathrm{Na}^{+}$excess 

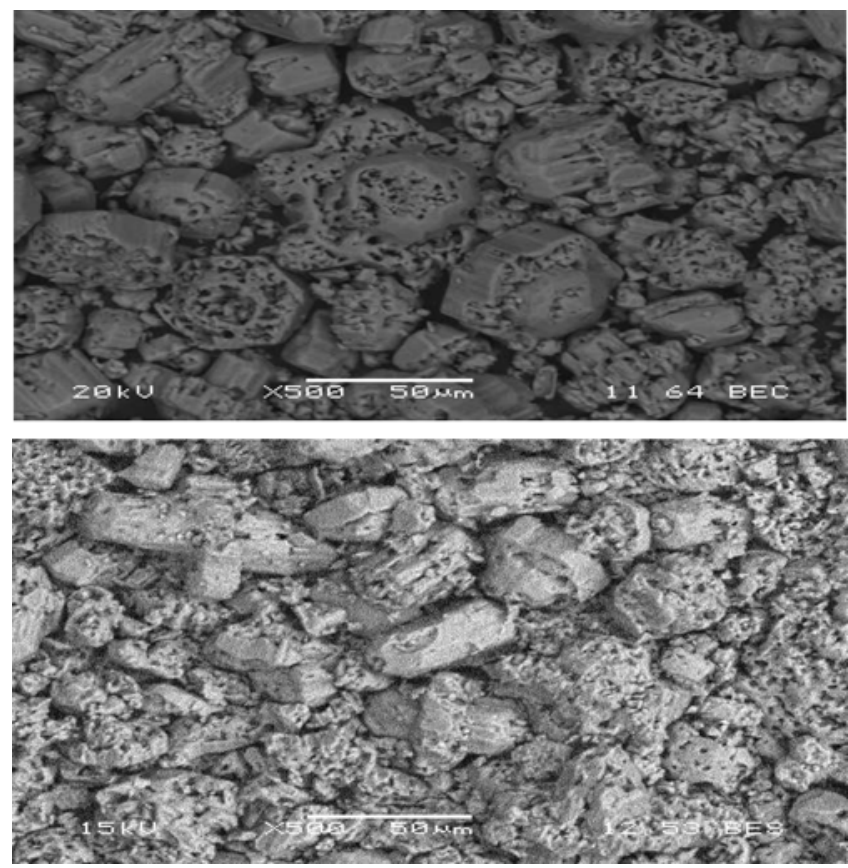

Figure 3. $\mathrm{SEM}$ micrographs of $\mathrm{Na}_{2} \mathrm{SiF}_{6}$ precipitate obtained with $10 \%$ excess $\mathrm{NaCl}$ (upper) and $30 \%$ excess $\mathrm{NaCl}$ (lower) $\left(\mathrm{T}=20^{\circ} \mathrm{C}, \mathrm{t}=40 \mathrm{~min} ., 300 \mathrm{rpm}\right)$

tion of $\mathrm{N}_{2} \mathrm{SiF}_{6}$ in $\mathrm{HCl}$ is the morphology of its crystals shown in Fig. 3 which appears to be eroded at higher $\mathrm{NaCl}$ excess.

However, the decrease in the yield, when $\mathrm{NaOH}$ was used could be related to the slow hydrolysis of the sodium hexafluorosilicate in water according to the following reaction $^{5,11}$ :

$\mathrm{Na}_{2} \mathrm{SiF}_{6}+4 \mathrm{NaOH} \rightarrow 6 \mathrm{NaF}+\mathrm{SiO}_{2}+2 \mathrm{H}_{2} \mathrm{O}$

\section{Effect of temperature}

The effect of temperature on the yield of $\mathrm{Na}_{2} \mathrm{SiF}_{6}$ was investigated at an excess of $25 \%$ for both $\mathrm{NaCl}$ and $\mathrm{NaOH}$ and a contact time of 40 minutes. From Figure 4 it can be seen that the increase of temperature, from $20^{\circ} \mathrm{C}$ to $40^{\circ} \mathrm{C}$, causesa slight increase in the yield, after that a slight decrease was observed. In the case of $\mathrm{NaCl}$ the

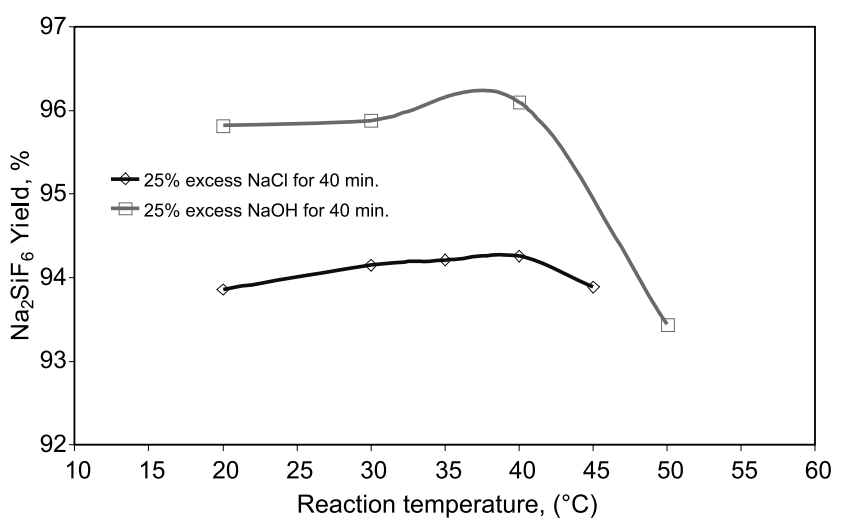

Figure 4. The effect of temperature on the yield of $\mathrm{Na}_{2} \mathrm{SiF}_{6}$ at $25 \%$ excess $\mathrm{Na}^{+}$and a reaction time of 40 minutes

Table 2. Comparison between yields of $\mathrm{Na}_{2} \mathrm{SiF}_{6}$ with and without seeding $\left(0.5 \mathrm{~g} \mathrm{Na}_{2} \mathrm{SiF}_{6}\right.$ seeding)

\begin{tabular}{|l|c|c|}
\hline \multirow{2}{*}{ Reagent } & \multicolumn{2}{|c|}{ Yield (wt \%) } \\
\cline { 2 - 3 } & with seeding & without seeding \\
\hline $\mathrm{NaCl}$ & 94.97 & 94.26 \\
\hline $\mathrm{NaOH}$ & 97.62 & 96.10 \\
\hline
\end{tabular}

highest yield of $\left(\mathrm{Na}_{2} \mathrm{SiF}_{6}\right)$ was obtained at a temperature $40^{\circ} \mathrm{C}$ reaching $94.24 \%$. The reason behind the drop in the yield may be due to the dissolution of the product at high temperature. Additionally, the $\mathrm{HCl}$ acid formed during the reaction increase the solubility of product and formation of gel material ${ }^{10}$. As for $\mathrm{NaOH}$ the highest yield of $\mathrm{Na}_{2} \mathrm{SiF}_{6}$ was also obtained at a temperature $40^{\circ} \mathrm{C}$ with a value of $96.1 \%$. With the further increase of temperature the yield was found to drop more significantly than that of $\mathrm{NaCl}$. This is probably related to the increase of solubility of $\mathrm{Na}_{2} \mathrm{SiF}_{6}$ in water with the increase of temperature ${ }^{13}$. Park et al. ${ }^{14}$ reported that solubility of $\mathrm{Na}_{2} \mathrm{SiF}_{6}$ in hot water is about $0.13 \mathrm{M}$

\section{Effect of seeding}

The effect of seeding on the precipitation and yield of $\mathrm{Na}_{2} \mathrm{SiF}_{6}$ was studied under the following conditions: 0.5

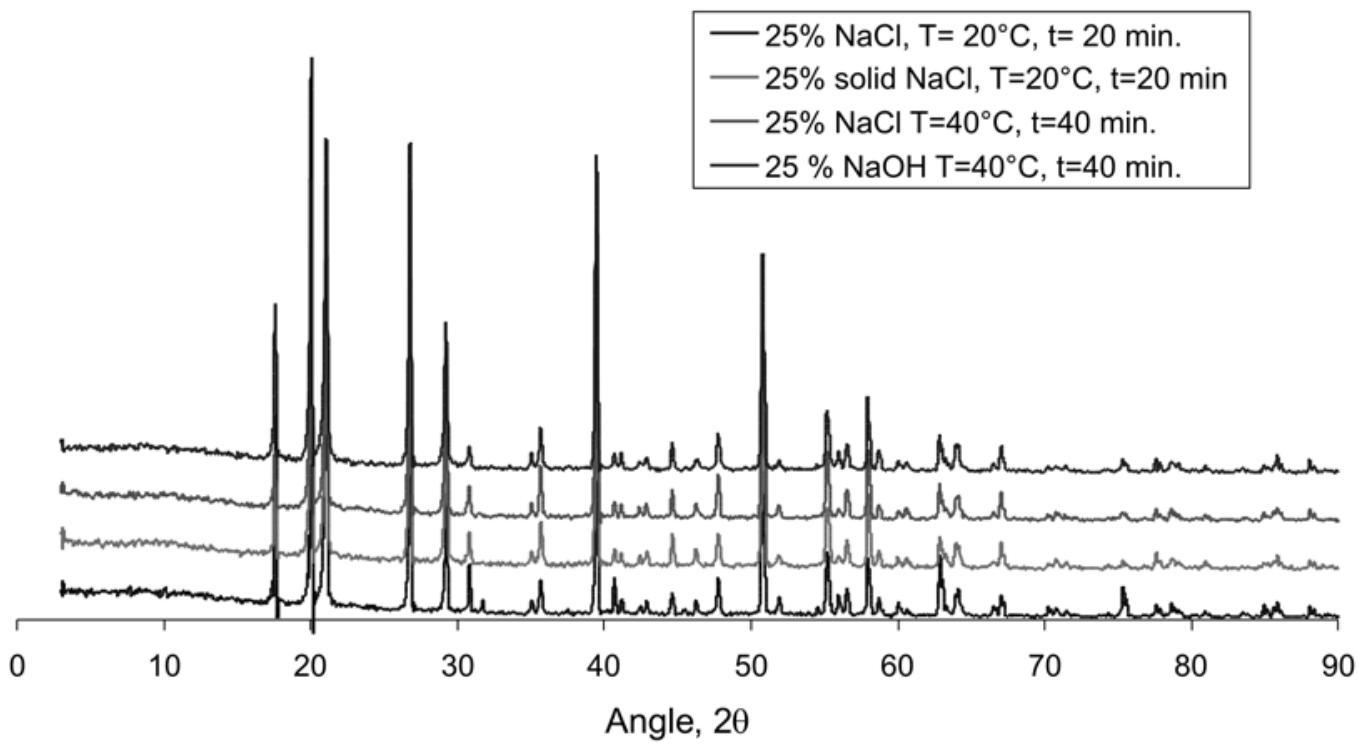

Figure 5. X-Ray diffraction patterns of the produced sodium fluorosilicate under different conditions 


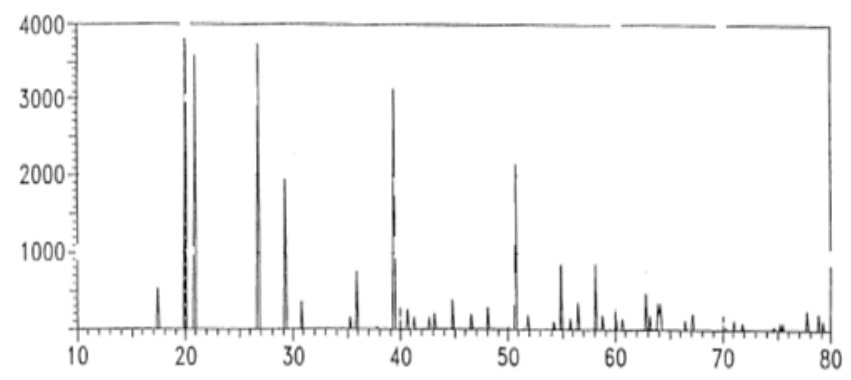

Figure 6. Standard X-ray diffraction pattern of $\mathrm{Na}_{2} \mathrm{SiF}_{6}{ }^{16}$

gram seeding of $\mathrm{Na} 2 \mathrm{SiF} 6$, temperature $40^{\circ} \mathrm{C}, 25 \%$ excess and 40 minutes contact time (Table 2). A slight increase of $\mathrm{Na}_{2} \mathrm{SiF}_{6}$ yield was obtained as a result of seeding for both $\mathrm{NaCl}$ and $\mathrm{NaOH}$. The seeding in the crystallization could change the crystal growth habits and crystal size distribution ${ }^{15}$.

\section{CHARACTERIZATION OF SOLID $\mathrm{Na}_{2} \mathrm{SiF}_{6}$}

\section{X-Ray Diffraction (XRD) analysis}

The product samples of $\mathrm{Na}_{2} \mathrm{SiF}_{6}$ which were prepared by the reaction of hexafluorosilicic acid with sodium chloride or sodium hydroxide were analyzed by X-Ray diffraction (XRD). Figure 5 below shows the XRD patterns of the produced $\mathrm{Na}_{2} \mathrm{SiF}_{6}$ which shows high purity crystalline sodium hexafluorosilicate as compared to the standard XRD patterns of $\mathrm{Na}_{2} \mathrm{SiF}_{6}$ shown in Fig. 6.

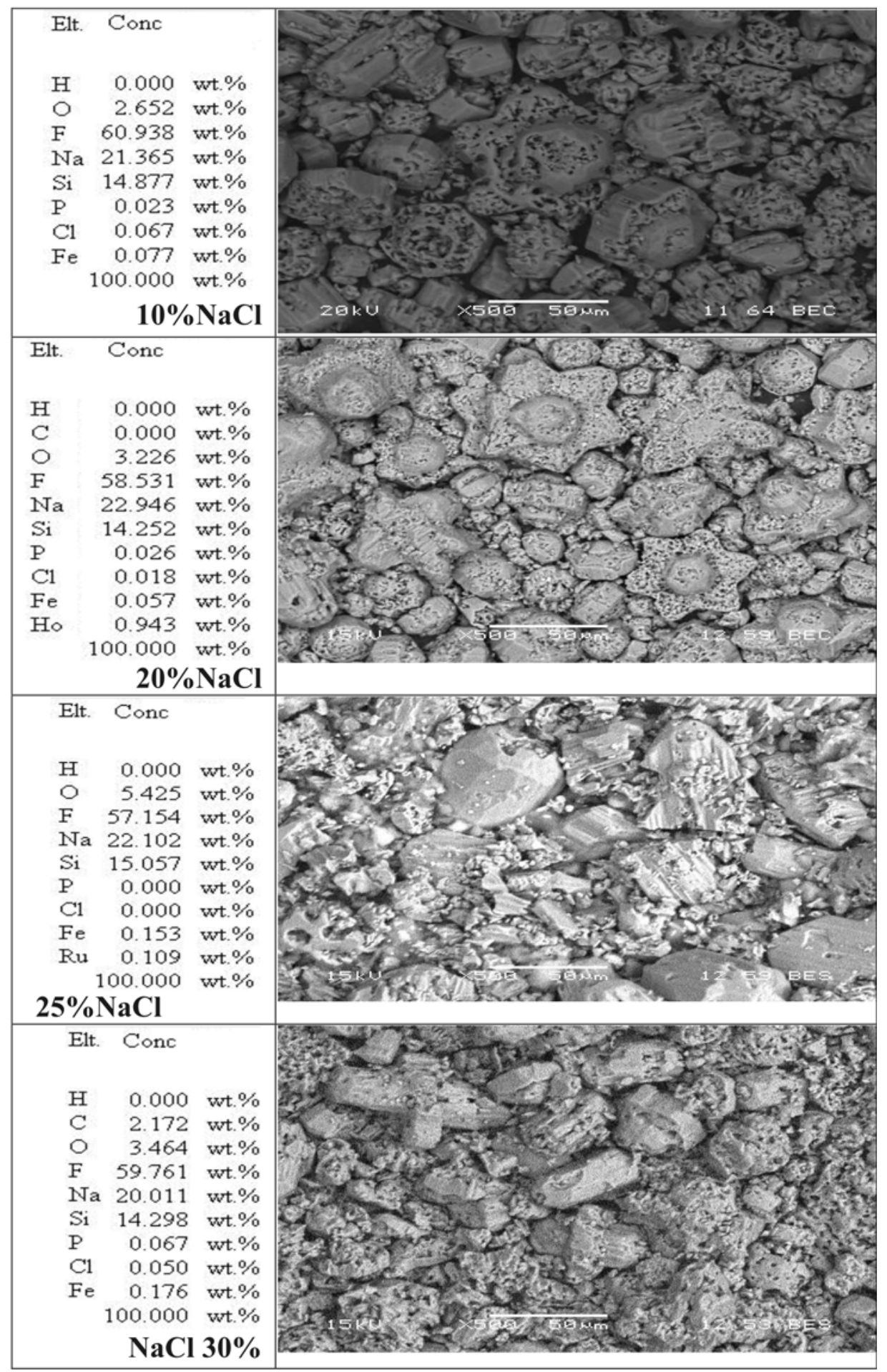

Figure 7. $\mathrm{SEM}$ micrographs and corresponding $\mathrm{XRD}$ analysis of the produced $\mathrm{Na}_{2} \mathrm{SiF}_{6}$ precipitate when $\mathrm{NaCl}$ was used 


\section{Scanning-Electron Microscope (SEM) analysis}

Figure 7 below shows SEM images and XRD analysis of sodium hexafluorosilicate crystals produced by reacting $\mathrm{H}_{2} \mathrm{SiF}_{6}$ with $\mathrm{NaCl}$ at a magnification of (X500). It can be seen that most crystals have a similar shape (hexagonal, six armed). All crystals are shown to be porous and the porosity or erosion increases with the increase of $\mathrm{NaCl}$ concentration. At concentrations of $\mathrm{NaCl}$ higher than $25 \%$, the $\mathrm{Na}_{2} \mathrm{SiF}_{6}$ crystals start to loose their six armed shape and become more corroded. As mentioned earlier, this could be due the back dissolution of sodium hexafluorosilicate by $\mathrm{HCl}$ formed, the concentration of which increases with the increase of $\mathrm{NaCl}$ excess.

Figure 8 below shows SEM images and XRD analysis of sodium hexafluorosilicate crystals produced by reacting $\mathrm{H}_{2} \mathrm{SiF}_{6}$ with $\mathrm{NaOH}$ at a magnification of (X500). It can be seen that there is a variation of particle size under all excess concentration and fine crystals formation are

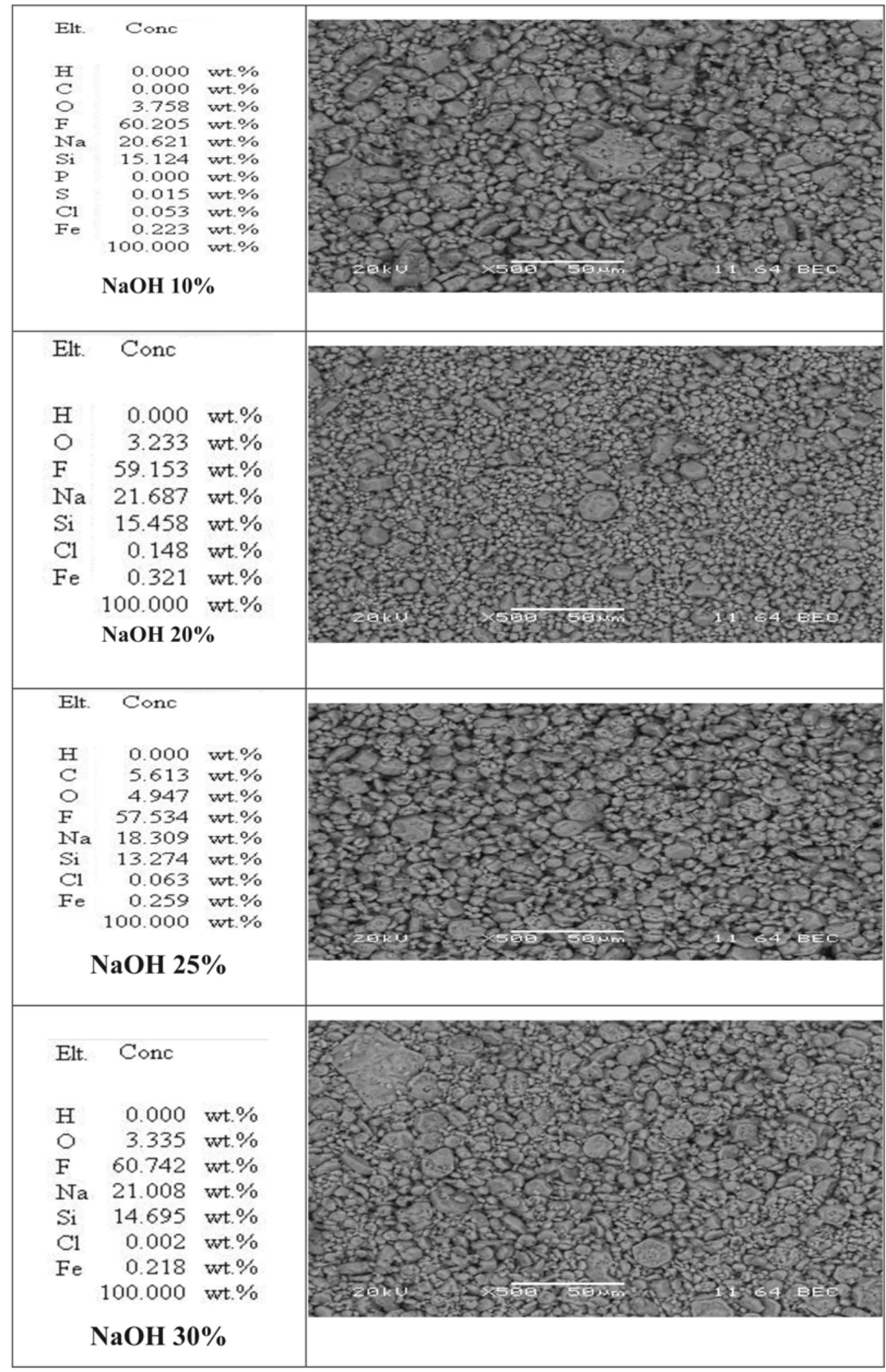

Figure 8. SEM micrographs and corresponding XRD analysis of the produced $\mathrm{Na}_{2} \mathrm{SiF}_{6}$ precipitate at different excess concentration of $\mathrm{NaOH}$ 
more predominant. Hexagonal crystals still can be seen but here they seem to be thinner than those obtained with $\mathrm{NaCl}$. Additionally, some crystals shapes are ice-like crystal and others are pyramidal with smooth faces and more compact. The erosion of precipitated crystals is much less compared to that of when $\mathrm{NaCl}$ was used. Furthermore, the XRD analysis reveals that the concentration of iron win the precipitate is higher than that when $\mathrm{NaCl}$ was used.

\section{X-Ray Fluorescence analysis (XRF)}

The product samples of Na2SiF6 which were prepared by the reaction of hexafluorosilicic acid with sodium chloride were analyzed using the XRF. The results of the analysis are summarized in Table 3. When the theoretical content of $\mathrm{F}, \mathrm{Na}$ and $\mathrm{Si}$ in $\mathrm{Na}_{2} \mathrm{SiF}_{6}$ is compared with the experimental values one can notice small variations. In particular there is extra fluoride and silicone present in the precipitate. This could suggest precipitation of silicates and some other fluorides in small quantities.

Table 3. X-Ray Fluorescence analysis for $\mathrm{Na}_{2} \mathrm{SiF}_{6}$ produced using $\mathrm{NaCl}$

\begin{tabular}{|l|c|l|l|l|l|}
\hline & Theoretical & test 1 & test 2 & test3 & test 4 \\
\hline $\mathrm{F} \%$ & 60.6 & 60.6 & 60.4 & 61.5 & 61.4 \\
\hline $\mathrm{Na} \%$ & 24.5 & 23.0 & 21.9 & 22.4 & 22.6 \\
\hline $\mathrm{Si} \%$ & 14.9 & 15.9 & 15.9 & 16.0 & 16.0 \\
\hline $\mathrm{P} \%$ & & 0.04 & 0.02 & 0.04 & 0.04 \\
\hline $\mathrm{Al} \%$ & & 0.02 & 0 & 0.02 & 0.03 \\
\hline $\mathrm{Ca} \%$ & & 0 & 0 & 0.02 & 0.02 \\
\hline $\mathrm{O} \%$ & & 0.33 & 1.64 & 0.02 & 0.022 \\
\hline $\mathrm{Cl} \%$ & & 0.10 & 0.08 & 0 & 0 \\
\hline $\mathrm{Fe} \%$ & & 0 & 0.061 & 0 & 0 \\
\hline
\end{tabular}

Test 1: Excess $25 \%$ solution, $20^{\circ}$ Cand $20 \mathrm{~min}$

Test 2: Excess $25 \%$ solid, $20^{\circ}$ Cand 20 min

Test 3: Excess $25 \%$ solution, $20^{\circ}$ Cand $40 \mathrm{~min}$

Test 4: Excess $25 \%$ solution + seed, $20^{\circ}$ Cand $20 \mathrm{~min}$

\section{CONCLUSION}

The effects of reaction conditions on the precipitation of sodium hexafluorosilicate produced from waste hexafluorosilicic acid of fertilizer industry were investigated in the current work. For $\mathrm{Na}_{2} \mathrm{SiF}_{6}$ precipitation from $\mathrm{H}_{2} \mathrm{SiF}_{6}$, two sodium sources were used; $\mathrm{NaOH}$ and $\mathrm{NaCl}$. The following conclusions could be drawn:

- The optimum reaction conditions were found as follows: excess sodium chloride or sodium hydroxide to hexafluorosilicic acid of $25 \%$, contact time 40 minutes and a reaction temperature of $40^{\circ} \mathrm{C}$.

- The highest $\mathrm{Na}_{2} \mathrm{SiF}_{6}$ yield was obtained when sodium hydroxide was used at the above mentioned reaction conditions with a yield value of $97.3 \%$.

$-\mathrm{XRF}$ and XRD analyses revealed that the use of $\mathrm{NaOH}$ for $\mathrm{Na}_{2} \mathrm{SiF}_{6}$ leads to contamination of the precipitate with iron, while when using sodium chloride the iron remains soluble and is washed out.

- The use of sodium chloride leads to the formation of coarser sodium hexafluorosilicate crystals. Additionally, these crystals were found porous and more eroded especially at

- high $\mathrm{NaCl}$ excess concentration;

- Increasing the initial temperature of the reactants to $50^{\circ} \mathrm{C}$ and above leads to the formation of gel product which could not be separated in simple filtration. The formation of gel may be due to a slight decomposition of the product or dissolution in the produced hydrochloric acid.

\section{LITERATURE CITED}

1. Ozsvath, D.L. (2008). Fluoride and environmental health: a review Rev. Environ. Sci. Biotechnol. 8(1), 59-79. DOI: 10.1007/ s11157-008-9136-9.

2. Pilat, M. (1935). Histological Researches into the Action of Insecticides on the Intestinal Tube of Insects. Bull. Entomol. Res. 26(02), 165-172. DOI: 10.1017/S0007485300038165.

3. Bulanov, A.D., Pryakhin, D.A. \& Balabanov, V.V. (2003). Preparation of High-Purity Silicon Tetrafluoride by Thermal Dissociation of $\mathrm{Na}_{2} \mathrm{SiF}_{6}$. Russ. J. Appl. Chem. 76(9), 1393-1395. DOI: 10.1023/B:RJAC.0000012654.22326.e5.

4. Carleton, K.L., Olson, J.M., \& Kibbler, A. (1983). Electrochemical Nucleation and Growth of Silicon in Molten Fluorides. J. Electrocheml. Soc., 130(4), 782-786 DOI: 10.1149/ 1.2119803 .

5. Wang, L., Tomura, S., Ohashi, S.M.F., Inukai, K. \& Maeda M. (2001). Synthesis of mesoporous silica material with sodium hexafluorosilicate as silicon source under ultralow surfactant concentration. J. Mater. Sci. Lett. 20, 277-280. DOI: $10.1023 / \mathrm{A}: 1006761926695$.

6. Leal-Cruz, A.L. \& Pech-Canul, M.I. (2006). In situ synthesis of $\mathrm{Si}_{3} \mathrm{~N}_{4}$ from $\mathrm{Na}_{2} \mathrm{SiF}_{6}$ as a silicon solid precursor. Mater. Chem. Phys. 98(1), 27-33. DOI: 10.1016/ j.matchemphys.2005.08.057.

7. Frayret, J., Castetbon, A., Trouve, G. \& Potin-Gautier, M. (2006). Solubility of $\left(\mathrm{NH}_{4}\right)_{2} \mathrm{SiF}_{6}, \mathrm{~K}_{2} \mathrm{SiF}_{6}$ and $\mathrm{Na}_{2} \mathrm{SiF}_{6}$ in acidic solutions. Chem. Phys. Lett. 427, 356-364. DOI:10.1016/ j.cplett.2006.06.044.

8. JPMC (2009). 56th Annual Report \& Financial Statments for the year 2009. Amman/Jordan: Jordan Phosphate Mines Co. PLC. 1-43.

9. Ghuge, K.D. \& R.R. Angadi (1987). Indian Journal of Technolology, 25, 187.

10. Pozin, M.E. (1989). Mineral Fertilizers Technology (in Russian). Leningrad: Khimia.

11. Sikdar, S.K. \& Moore, J.H. (1980). Recovery of hydrofluoric acid from fluosilicic acid with high $\mathrm{pH}$ hydrolysis. Patent No. 4,213,951 USA.

12. Lide, D.R. (2010). ed. ^ eds. CRC Handbook of Chemistry and Physics. 90th Edition ed. CRC.

13. Schroder, F. (1992). in Gmelin Handbook of inorganic and Organometallic Chemistry: Si, Suppl. Springer-Verlag: Berlin. 300

14. Park, H.C., Ryu, B.K., Park, S.S., Shin, H.G., Lee, S.H. \& You, Y.W. (1997). Recycling of waste HF solution by $\mathrm{Na}_{2} \mathrm{CO}_{3}$ treatment for use in cleaning of TV panel glass. J. Mater. Sci. Lett. 17(1), 11-13. DOI: 10.1023/A:1006525204074.

15. Ruixiang, Z. (2005). Process optimization in batch crystallization of sodium fluosilicate. Cryst. Res. Technol. 40(3), 243 -247. DOI: 10.1002/crat.200410332.

16. Bulko, J.B. \& Smyser, B.M. (2000). Method for producing silicon tetraflouride from uranium oxyflouride. Patent No. WO 00/58212. 